\title{
Numerical simulation of minor losses coefficient on the example of elbows
}

\author{
Smyk Emil", Mrozik Dariusz, Olszewski Łukasz, Peszyński Kazimierz \\ UTP University of Science and Technology, Faculty of Mechanical Engineering, Poland
}

\begin{abstract}
Determining of minor losses coefficient is very complicated problem. Analytical methods are often very difficult and experimental methods are very expensive and time-consuming. Consequently, the use of numerical methods seems to be a good solution, but there are no publications describing this issue. Therefore, the paper is describing the numerical method of determining the minor loss coefficient $\xi$ on the example of elbows with circular cross-section.
\end{abstract}

\section{Introduction}

Pneumatic, hydraulic or ventilating systems are just a few examples of systems in which various types of fittings are used. Examples of fittings used in different systems are: elbow, bow, diffuser, confusor, tee or valve [1]. One of the most important parameters of all type of fittings is minor loss coefficient $\xi$.

Minor $(\xi)$ and major/head $(\lambda)$ loss coefficients are used to calculation of pressure losses in different kind of systems. Major loss coefficient $\lambda$ refers to energy losses caused by friction, while minor loss coefficient $\xi$ to energy losses caused by flow disorder. However, during the major loss coefficient $\lambda$ is designate for practically every case (experimental models, practically independent of channel shape), the minor loss coefficient $\xi$ only for specific cases (tables with specific fittings).

Minor loss coefficient $\xi$ can be defined in an analytical, experimental [2, 3] or numerical [4-6] way. However, it should be noted that analytical way is very complicated and can't be used in any case. The most universal and generally used is the experimental way. It is time-consuming and expensive process, because the minor loss coefficient $\xi$ is dependent on Reynolds number, duct dimensions and other [7]. For these reason design and use in real object of new type of ducts (with another than circular or rectangular cross-section) is unprofitable. Amount of work and money necessary to designate a minor loss coefficient $\xi$ for all new fittings is disproportionate to the potential benefits. Taking into consideration, it should be found numerical way to determination of minor loss coefficient $\xi$ for different kind of fittings. It would reduce the amount of experimental research.

In this investigation is presented numerical way of minor loss coefficient $\xi$ designation for elbow with circular cross-section. This kind of fitting is commonly used in different systems and its minor loss coefficients $\xi$, can be found in literature $[7,8]$ and also in standards
[9]. It must be noted that the authors failed to find articles dedicated the issue presented in this paper.
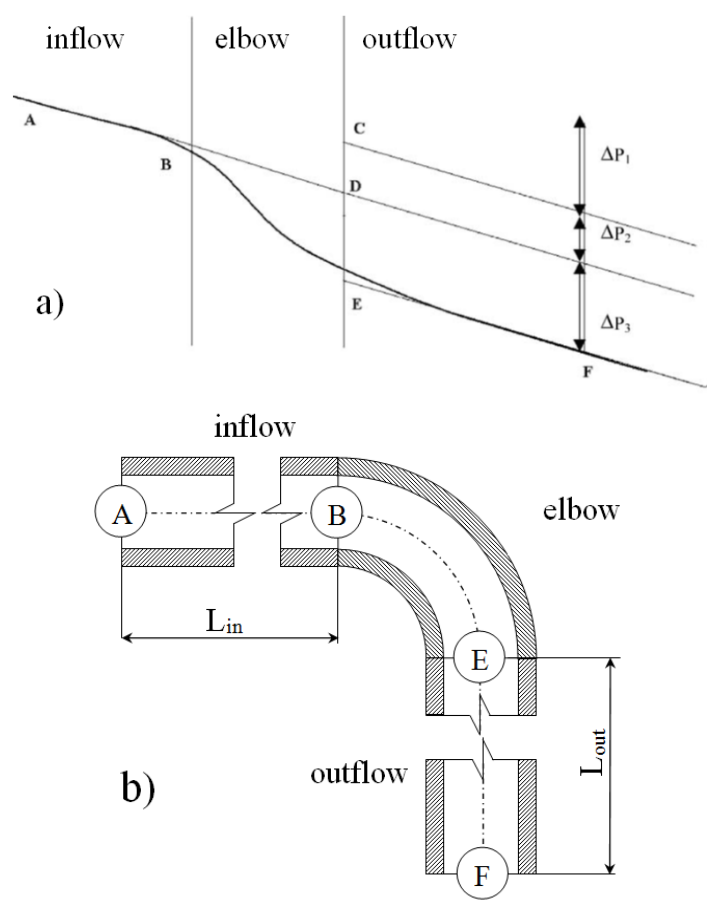

Fig.1 a) Schematic variation of centerline pressure in duct with bend with identification of various pressure drop components [6], b) model of measurement system

\subsection{Minor loss coefficient for elbow- methodology of determination}

The determination of minor loss coefficient $\xi$ for elbow is performed by measuring the static pressure on the duct section with elbow (fig. 1b). As can be seen the pressure different at the points $\mathrm{A}$ and $\mathrm{F}$ is caused by (fig. 1a):

- major losses in the inflow and outflow $\Delta p_{i}$;

- major losses in elbow $\Delta p_{2}$;

- minor losses caused by elbow $\Delta p_{3}$.

\footnotetext{
Corresponding author: emil.smyk@utp.edu.pl
} 
Because the major losses in the inflow and outflow $\Delta p_{1}$ are known and can be calculate, based on the static pressure measurement in point $\mathrm{A}$ and $\mathrm{F}$ the pressure loss coefficient $K_{b}$ for elbow can be calculated [6]:

$$
K_{b}=\frac{2\left(\Delta p_{2}+\Delta p_{3}\right)}{\rho v^{2}}
$$

where $\rho$ is density of working fluid and $v$ is mean velocity of working fluid. Eq 1 can be also expressed as:

$$
K_{b}=\frac{p_{A}-p_{F}}{\rho v^{2}}-\lambda \frac{l_{\text {in }}+l_{\text {out }}}{D_{h}}
$$

where $l_{\text {in }}$ is length of inlet, $l_{\text {out }}$ is length outlet, and $D_{h}$ is hydraulic diameter. The hydraulic diameter $D_{h}$ can be calculated from:

$$
D_{h}=\frac{4 \cdot A}{P}
$$

where $A$ is cross-sectional area and $P$ is wetted perimeter of the cross-section. In case of ventilation systems $P$ is equal duct perimeter. For a circular duct the hydraulic diameter $D_{h}$ is simply the diameter of the duct.

The minor loss coefficient $\xi$ can be calculated by reduction of pressure loss coefficient $K_{b}$ by major losses in elbow $\Delta p_{2}$. Minor loss coefficient $\xi$ can be calculated from [6]:

$$
\xi=K_{b}-\lambda C \theta
$$

where $C$ is the curvature ratio and $\theta$ is bend angle in radian.

It must be noted that the length of inlet and outlet must be equal or longer than 10 hydraulic diameter $D_{h}$. This length allows for the disappearance of the disorder caused by fitting.

During investigation Reynolds number $R e$ was define as:

$$
R e=\frac{v D_{h}}{\mu}
$$

where $\mu$ is kinematic viscosity of working fluid.

\section{Numerical simulation}

Numerical simulation was made in Ansys Fluent software. The first step of calculation was choice of simulation model. Calculated minor loss coefficient $\xi$, according to eq. 2 and 4, is depended on the adopted major loss coefficient $\lambda$. Consequently, it was decided to choose the turbulent model gives major loss coefficient $\lambda$ results consistent with the theory. The next stage was designation of the minor loss coefficient $\xi$ for elbows with selected parameters. All simulation was made with air as working fluid without compressibility.

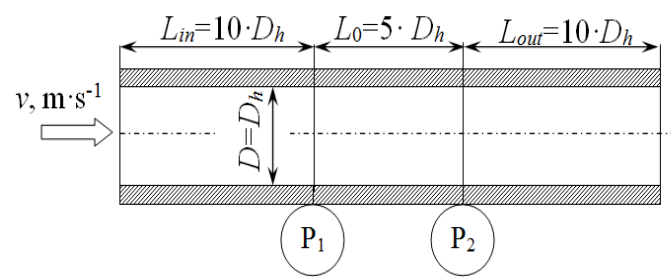

pressure outlet

Fig. 2 Model of stright duct

\subsection{Preliminary research}

In this part of research was used three generally used turbulence models (Spalart- Allmaras, $\mathrm{k}-\varepsilon$ and $\mathrm{k}-\omega$ ) to determine how they simulate major losses. For this purpose, a straight duct model was created. The model was consist from inlet $L_{i n}$, measuring section $L_{0}$ and outlet $L_{\text {out }}$, lengths as shown in fig. 2. The plane of symmetry was used in the model, and during meshing was used only hexadron elements.
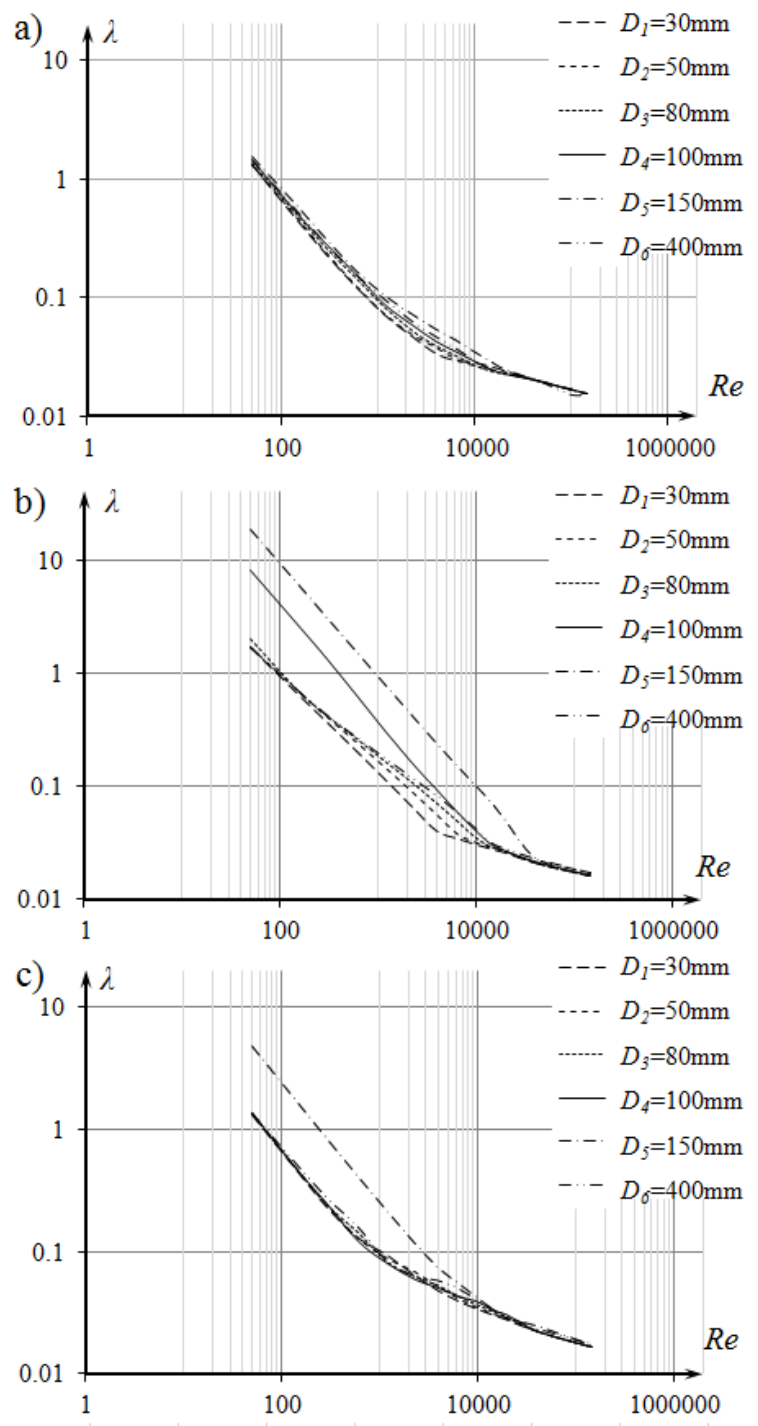

Fig. 3 Dependence between major loss coefficient $\lambda$ and Reynolds number $R e$ for a) Spalart- Allamars turbulence model, b) k- $\varepsilon$ turbulence model, c) k- $\omega$ turbulence model

Simulation was made for six different diameter $D$ $\left(D_{I}=30, D_{2}=50, D_{3}=80, D_{4}=100, D_{5}=150, D_{6}=400, \mathrm{~mm}\right)$ and fourteen different Reynolds number $(R e=50,150$, $300,600,1200,2300,4000,6500,10^{4}, 1.45 \cdot 10^{4}$, $2 \cdot 10^{4}, 4 \cdot 10^{4}, 10^{5}, 1.5 \cdot 10^{5}$ ). Based on the simulation dependence between major loss coefficient $\lambda$ and Reynolds number $R e$ was designated for different turbulence model and diameter. This dependence is shown in fig. 3, logarithmic scale was used. Additionally comparison of averaged major loss coefficients $\lambda$ from simulations and major loss coefficient $\lambda$ calculated on the basis of theory [1, 7-9].As can be seen in the fig. 3 the 
results are very different. The first difference is dependence of results from diameter. In case of Spalart- Allmaras turbulence model the calculated major loss coefficients $\lambda$ are similar and only Reynolds number $R e$ influences their value (fig. 3a). It is consistent with the theory [1, 7-9]. However, in the case of $\mathrm{k}-\varepsilon$ turbulence model (fig. 3b) the minor loss coefficient $\lambda$ for diameter $D_{1}$ and $D_{5}$ stand out from the rest of results, and they values are bigger than other. In case $D_{1}$ for $R e<2 \cdot 10^{4}$ and in case $D_{5}$ for $R e<4 \cdot 10^{3}$.

For k- $\omega$ turbulence model results for only one diameter stand out from the rest. The major loss coefficients $\lambda$ for diameter $D_{5}$ are bigger than other in case $\operatorname{Re}<10^{4}$.

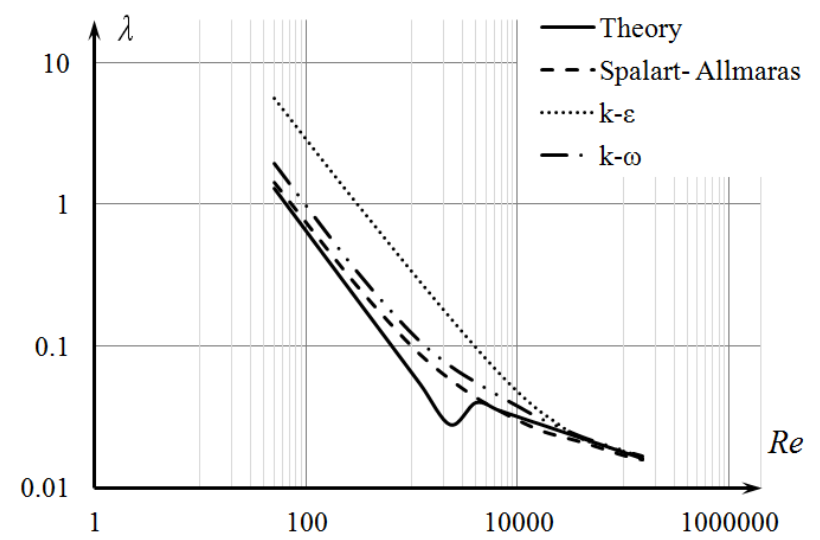

Fig. 4 Comparision of avereged major loss coefficients $\lambda$ from simulation with theoretical [1,7-9]

As can be seen on the fig. 4 the averages major loss coefficients $\lambda$ for Spalart- Allamars turbulence model are the most similar to the theoretical values. However in case of big Reynolds number $R e>2 \cdot 10^{4}$ all used turbulence models give similar convergence of results with theory.

Based on the above results Spalart- Allmaras turbulence model was chosen to simulations which the determination of minor loss coefficient $\xi$ is purpose. The authors are aware that this model may not be the best model to simulation of turbulence, which arise in the elbow. However, due to local velocity changes, at the wall in elbow and behind them, it seems that the use of model which simulates the most accurate major losses will help to improve the accuracy of the results.

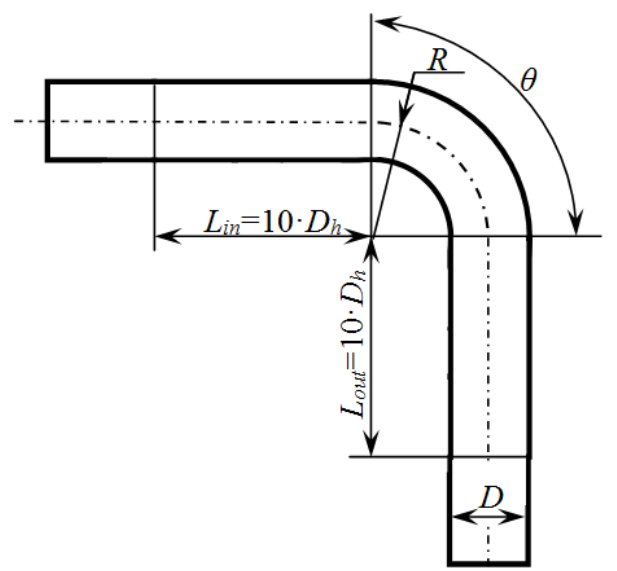

Fig. 5 Model of elbow with inlet and outlet channel

\subsection{Main simulation}

\subsubsection{Simulation model and parameters}

Simulation model is shown in fig. 5. Before and behind the elbow was modelled inlet and outlet channel of length $L_{i n}=L_{\text {out }}=10 \cdot D_{h}$, where hydraulic diameter is equal normal duct diameter $D_{h}=D$. The diameter of duct $D=400 \mathrm{~mm}$ was chose in such a way as to have the least effect on the designated minor loss coefficient $\xi$ (in [7] has been shown that for duct diameter $D<300$ the minor loss coefficient $\xi$ isn't constant and it is strongly dependent on diameter $D$ ). The models were made in different version for $\theta=20,30,45,60,75$ and $90^{\circ}$ and for ratio of elbow ratio to duct diameter $R / D=0.5,0.75,1$, 1.5, 2 and 2.5. On the end of duct was used boundary layer pressure outlet, and on the inlet of duct velocity inlet was selected as to Reynolds number was equal $R e=10^{4}, 2 \cdot 10^{4}, 4 \cdot 10^{4}, 10^{5}$ or $1.5 \cdot 10^{5}$.

As above mentioned, 36 different models were made and each was examine for 5 different velocity. This allows you to create a table with minor loss coefficients $\xi$ for a elbow with circular cross-section, which is similar to tables found in the literature [1,7-9].

Minor loss coefficients $\xi$ were calculated from formulas (2) and (4). During calculation major loss coefficient $\lambda$ was adopted from preliminary research.

\subsubsection{Simulation results}

As mentioned simulation was made with five different velocity for each from 36 models. Exemplary results of calculated minor loss coefficients $\xi$ for elbow $\theta=75^{\circ}$ is presented in table 1 .

Table 1. Calculated minor loss coefficients $\xi$ for elbow $\theta=75^{\circ}$ for different Reynolds number $R e$ and their average and standard deviation

\begin{tabular}{|c|c|c|c|c|c|c|}
\hline \multirow{2}{*}{$R / D$} & \multicolumn{5}{|c|}{ Reynolds number $R e$} & \multirow{2}{*}{$\begin{array}{c}\text { Average } \\
\pm \text { standard } \\
\text { deviation }\end{array}$} \\
\hline & $10^{4}$ & $2 \cdot 10^{4}$ & $4 \cdot 10^{4}$ & $10^{5}$ & $1.5 \cdot 10^{5}$ & \\
\hline 0.5 & 0.51 & 0.50 & 0.52 & 0.51 & 0.51 & $0.51 \pm 0.0071$ \\
\hline 0.75 & 0.29 & 0.24 & 0.24 & 0.22 & 0.21 & $0.24 \pm 0.0308$ \\
\hline 1 & 0.25 & 0.19 & 0.18 & 0.16 & 0.15 & $0.186 \pm 0.0391$ \\
\hline 1.5 & 0.19 & 0.16 & 0.15 & 0.13 & 0.12 & $0.15 \pm 0.0274$ \\
\hline 2 & 0.16 & 0.13 & 0.14 & 0.12 & 0.11 & $0.132 \pm 0.0192$ \\
\hline 2.5 & 0.14 & 0.10 & 0.10 & 0.08 & 0.08 & $0.10 \pm 0.0245$ \\
\hline
\end{tabular}

In table 1 are presented minor loss coefficients $\xi$ calculated for different Reynolds number Re. The results are rounded to the second decimal place. Additionally it was calculated their average and standard deviation. As can be seen the minor loss coefficient $\xi$ is dependent on $R / D$ ratio (this is an obvious and well-known fact) and Reynolds number $R e$. Generally the bigger the Reynolds number $R e$, the smaller the minor loss coefficient $\xi$. The results for the same $R / D$ ratio are very different and they can vary by as much as $40 \%$ from each other 
for different Reynolds number $R e$ e.g. for $R / D=1$ if $R e=10^{4}$ then $\xi=0.25$ and if $R e=1.5 \cdot 10^{5}$ then $\xi=0.15$

It has big influence on presented in table 1 average of results and them standard deviation. In case of mentioned earlier elbow $\theta=75^{\circ}, R / D=1$ the standard deviation is about $21 \%$ of the average value of designated minor loss coefficients $\xi$. To highlight how the results differ from each other in table 2 are showed what percentage of the average value is the standard deviation.

Table 2. Ratio of absolute value of standard deviation to the average value expressed in percent

\begin{tabular}{|c|c|c|c|c|c|c|}
\hline \multirow{2}{*}{$\mathbf{R} / \mathbf{D}$} & \multicolumn{6}{|c|}{ Angle $\boldsymbol{\theta}$} \\
\cline { 2 - 7 } & $\mathbf{2 0}$ & $\mathbf{3 0}^{\circ}$ & $\mathbf{4 5}^{\circ}$ & $\mathbf{6 0}^{\circ}$ & $\mathbf{7 5}^{\circ}$ & $\mathbf{9 0}^{\circ}$ \\
\hline $\mathbf{0 . 5}$ & $29.88 \%$ & $42.70 \%$ & $4.32 \%$ & $13.36 \%$ & $1.39 \%$ & $0.96 \%$ \\
\hline $\mathbf{0 . 7 5}$ & $30.62 \%$ & $40.16 \%$ & $23.16 \%$ & $33.72 \%$ & $12.84 \%$ & $9.48 \%$ \\
\hline $\mathbf{1}$ & $36.38 \%$ & $39.46 \%$ & $32.71 \%$ & $33.72 \%$ & $21.03 \%$ & $16.39 \%$ \\
\hline $\mathbf{1 . 5}$ & $30.99 \%$ & $34.58 \%$ & $28.04 \%$ & $33.72 \%$ & $18.26 \%$ & $12.65 \%$ \\
\hline $\mathbf{2}$ & $30.99 \%$ & $31.11 \%$ & $25.25 \%$ & $31.11 \%$ & $14.57 \%$ & $12.04 \%$ \\
\hline $\mathbf{2 . 5}$ & $67.71 \%$ & $59.43 \%$ & $36.36 \%$ & $35.94 \%$ & $24.49 \%$ & $20.79 \%$ \\
\hline
\end{tabular}

As can be seen in the table 2 the results was significantly different from each other. The large value in table 2 tells us that the standard deviation was considerable in relation to average value and therefore it mean that during simulation the Reynolds number $R e$ has huge influence on the designed minor loss coefficient $\xi$. It can be seen that this dependence is the stronger the lower the angle $\theta$ and the bigger the ratio $R / D$ is. This is a negative phenomenon which influence which negatively affects the quality of results. However, despite this it was decided compare the results obtained from the simulations with the results from the literature [8]. The average values of results are presented in table 3 and minor loss coefficients $\xi$ values from literature are presented in table 4 .

It can be seen that the value of calculated and literary minor loss coefficients $\xi$ are close to each other especially for elbow with $\theta=75^{\circ}$ and $\theta=90^{\circ}$ and for elbow with ratio $R / D \geq 1.5$. To better illustrate in table 5 are presented modulus of relative errors of coefficients from simulation (table 3 ) relative to coefficients from [8] (table 4). Relative error was calculated from:

$$
e=\left|\frac{\xi_{c}-\xi_{l}}{\xi_{l}}\right| \cdot 100 \%
$$

where $\xi_{c}$ is minor loss coefficients from calculation and $\xi_{l}$ is minor loss coefficients from [8] for specific elbow.

In table 3 are presented rounded values. However during table 5 creation was used not rounded values, which was calculated on base of simulation

Additionally in the table 5 are marked with a gray background the cases where the relative error is smaller than $30 \%$. Authors took this error threshold as being sufficient to recognize the results as correct.
As mentioned earlier results for elbow with $\theta=75^{\circ}$ and $\theta=90^{\circ}$ and for elbow with ratio $R / D \geq 1.5$ are very good and except elbow $\theta=20^{\circ} R / D=2$ and elbow $\theta=45^{\circ}$ $R / D=2.5$ minor loss coefficients $\xi$ for all elbows in this area are very close to literary value (relative error smaller than $30 \%$ ). In case of elbow with small $R / D$ ratio and small angle the calculations results are completely different for example for elbow $\theta=20^{\circ} R / D=0.5$ or elbow $\theta=20^{\circ} R / D=2$.

On this basis it can be stated that the proposed method of simulation, of minor loss coefficients $\xi$ in elbow, gives correct results only for elbow with a large angle or with a large ratio $R / D$. However high correlation of the results to the Reynolds number $R e$ is a big inconvenience. In addition, it requires an additional check for other fittings.

Table 3. Designated from the simulations minor loss coefficients $\xi$ for elbow with circular cross section

\begin{tabular}{|c|c|c|c|c|c|c|}
\hline \multirow{2}{*}{ R/D } & \multicolumn{7}{|c|}{ Angle $\boldsymbol{\theta}$} \\
\cline { 2 - 7 } & $\mathbf{2 0}^{\circ}$ & $\mathbf{3 0}^{\circ}$ & $\mathbf{4 5}^{\circ}$ & $\mathbf{6 0}^{\circ}$ & $\mathbf{7 5}^{\circ}$ & $\mathbf{9 0}^{\circ}$ \\
\hline $\mathbf{0 . 5}$ & 0.03 & 0.05 & 0.14 & 0.30 & 0.51 & 0.74 \\
\hline $\mathbf{0 . 7 5}$ & 0.04 & 0.06 & 0.10 & 0.17 & 0.24 & 0.30 \\
\hline $\mathbf{1}$ & 0.05 & 0.07 & 0.10 & 0.15 & 0.19 & 0.21 \\
\hline $\mathbf{1 . 5}$ & 0.05 & 0.07 & 0.11 & 0.13 & 0.15 & 0.15 \\
\hline $\mathbf{2}$ & 0.05 & 0.07 & 0.07 & 0.12 & 0.13 & 0.13 \\
\hline $\mathbf{2 . 5}$ & 0.03 & 0.05 & 0.11 & 0.10 & 0.10 & 0.09 \\
\hline
\end{tabular}

Table 4. The minor loss coefficients $\xi$ for elbow with circular cross section from [8]

\begin{tabular}{|c|c|c|c|c|c|c|}
\hline \multirow{2}{*}{$\mathbf{R} / \mathbf{D}$} & \multicolumn{7}{|c|}{ Angle $\boldsymbol{\theta}$} \\
\cline { 2 - 7 } & $\mathbf{2 0}^{\circ}$ & $\mathbf{3 0}^{\circ}$ & $\mathbf{4 5}^{\circ}$ & $\mathbf{6 0}^{\circ}$ & $\mathbf{7 5}^{\circ}$ & $\mathbf{9 0}^{\circ}$ \\
\hline $\mathbf{0 . 5}$ & 0.22 & 0.32 & 0.43 & 0.55 & 0.64 & 0.71 \\
\hline $\mathbf{0 . 7 5}$ & 0.10 & 0.15 & 0.20 & 0.26 & 0.30 & 0.33 \\
\hline $\mathbf{1}$ & 0.07 & 0.10 & 0.13 & 0.17 & 0.20 & 0.22 \\
\hline $\mathbf{1 . 5}$ & 0.05 & 0.07 & 0.09 & 0.12 & 0.14 & 0.15 \\
\hline $\mathbf{2}$ & 0.04 & 0.06 & 0.08 & 0.10 & 0.12 & 0.13 \\
\hline $\mathbf{2 . 5}$ & 0.04 & 0.05 & 0.07 & 0.09 & 0.11 & 0.12 \\
\hline
\end{tabular}

Table 5. Modulus of relative error of coefficients from simulation relative to coefficients from [8]

\begin{tabular}{|c|c|c|c|c|c|c|}
\hline \multirow{2}{*}{ R/D } & \multicolumn{6}{|c|}{ Angle $\boldsymbol{\theta}$} \\
\cline { 2 - 7 } & $\mathbf{2 0}^{\circ}$ & $\mathbf{3 0}^{\circ}$ & $\mathbf{4 5}^{\circ}$ & $\mathbf{6 0}^{\circ}$ & $\mathbf{7 5}^{\circ}$ & $\mathbf{9 0}^{\circ}$ \\
\hline $\mathbf{0 . 5}$ & $86.7 \%$ & $85.1 \%$ & $67.3 \%$ & $44.7 \%$ & $20.2 \%$ & $4.2 \%$ \\
\hline $\mathbf{0 . 7 5}$ & $59.9 \%$ & $58.6 \%$ & $48.4 \%$ & $34.4 \%$ & $20.2 \%$ & $7.7 \%$ \\
\hline $\mathbf{1}$ & $34.0 \%$ & $32.6 \%$ & $19.4 \%$ & $13.3 \%$ & $6.8 \%$ & $3.1 \%$ \\
\hline $\mathbf{1 . 5}$ & $3.3 \%$ & $6.3 \%$ & $17.1 \%$ & $12.2 \%$ & $6.8 \%$ & $0.3 \%$ \\
\hline $\mathbf{2}$ & $33.3 \%$ & $24.6 \%$ & $8.7 \%$ & $24.4 \%$ & $9.8 \%$ & $3.4 \%$ \\
\hline $\mathbf{2 . 5}$ & $13.4 \%$ & $9.4 \%$ & $58.0 \%$ & $7.6 \%$ & $10.0 \%$ & $24.8 \%$ \\
\hline
\end{tabular}


It must be noted that obtained results was compare to data included in [8]. This may seem dubious in terms of scientific value. However, in the world's publications there are missing articles dealing with minor losses (omitting few articles like [2-6]). Research group, to which the authors of this article belong, deals with the issue of minor losses in ventilation ducts. Initial results of research are presented in [10-12].

In [6] are presented methods of minor losses $\xi$ calculation in elbow for different Reynolds number. However, in work [6] the results of presented calculations aren't compared to experimental data and refer to elbow with very small value of hydraulic diameter $D_{h}$ (paper [6] refers to channels in fuel cell stacks). For this reason presented in this investigations results can't be compared to data from [6].

\section{Conclusion}

In this article is presented method of simulation of minor loss coefficients $\xi$ in elbow with circular cross section. It has been shown that this method gives satisfactory results in case of some tested models. Presented results needs additionally research that will help make a results independent from Reynolds number $R e$, what may increase quality of results.

Additionally during the simulation the different types of turbulence models were tested how they simulate the head losses.

Please note that the presented method is intended to simplify the testing process of the fittings and to assist the experimental methods

\section{Acknowledgment}

Scientific work financed from the budget for science in the years2015/2018 as a research project within the program under the name "Diamond Grant "

Authors also received institutional support BSM - 60/2017 granted by Faculty of Mechanical Engineering of UTP University of Science and Technology.

\section{References}

1 A. Pełcha, Wentylacja i klimatyzacja - podstawy (Polish: Wentilation and air conditioning- base) (Oficyna Wydawnicza Politechniki Wrocławskiej, Wrocław, 2008)

2 K. Strzelecka, K. Jeżowiecka-Kabsch, Ochrona środowiska 30, 2 (2008)

3 Ł. Mika, Inżyn. i Apara. Chemi. 49, 1 (2010)

4 A.S. Kheireddine, M.H. Sanda, S.H. Chaturvedi, T.O. Mohieldin, Energy 22, 4 (1997)

5 G. Gan, S.B. Riffat, Applied Energy. 54, 2 (1996)

6 S. Maharudrayya, S. Jayanti, A.P. Deshpande, J. of Power Sour. 138, 1-2 (2004)

7 T. Klinke, Wentylacja, tablice do obliczeń strat ciśnienia (Polish: Ventilation, pressure loss calculation boards) (Oficyna Wydawnicza Politechniki Warszawskiej, Warszawa, 2007)

8 J. Hendiger, P. Ziętek, M. Chlidzinska, Wentylacja $i$ klimatyzacja. Materiaty pomocnicze do projektowania (Polish: Wentilation and air conditioning. Design aids) (Venture Industries Sp. z.o.o., Warszawa, 2013)

9 Polish standard PN-76 M-34034

10 E. Smyk, D. Mrozik, S. Wawrzyniak, K. Peszyński, Eng. Mech. 2017 (post-conference materials), 882885 (2017)

11 K. Peszyński, Ł. Olszewski, E Smyk, T. Kasprowicz, Eng. Mech. 2017 (post-conference materials), 50-53 (2017)

12 K. Peszyński, D. Perczyński, E Smyk, P. Kolber, Eng. Mech. 2017 (post-conference materials), 770773 (2017) 